\title{
The Development of the Writing Robot to Support the Balinese Script Culture
}

\author{
N.N. H. Puspita ${ }^{1}$, G. Indrawan ${ }^{2}$, N. Sukajaya ${ }^{3}$ \\ \{mangary86@gmail.com¹ ${ }^{1}$, gindrawan@undiksha.ac.id ${ }^{2}$, sukajaya@undiksha.ac.id ${ }^{3}$ \} \\ Department of Computer Science, Graduate Program, Ganesha University of Education, Bali, \\ Indonesia $^{123}$
}

\begin{abstract}
The development of Balinese script writer robot is one effort to preserve Balinese culture especially Balinese script which has increasingly limited its scope of use because of the complicated writing system. This research is a continuation of the development of Latin transliteration algorithm to Balinese Letter-based Unicode Balinese script developed with Correspondent's transliteration machine model, called LBtrans application. This study aims to be able to integrate LBTrans application with character writer robot, so that the transliteration result can be written by robot. The robot that is used is mDrawbot mScara lego robot version. Communication between applications and robots uses a web server to temporarily store transliterated results. Tests in this study were conducted in two stages, the first is transliteration algorithm testing performed based on Sadewa's test document covering all aspects of Balinese script writing, which were 152 case forms, ranging from characters, syllables, sentences and paragraphs. The test results show the algorithm has an accuracy of $98.01 \%$. The second test is with robots, where the test results show the robot successfully wrote the transliteration of Balinese script well in the case of characters, syllables, words. As for the sentence that has more than three words the result is undefined because the picture is not clear. LBtrans has weaknesses, where writing for e characters that have the same grapheme but different phonemes, still have different inserts. The weakness of the Balinese script writer robot is the weakness of his writing in the form of two lines. Based on this research, future research is expected to apply machine mining to provide ease of user input Latin text so that the transliteration can appear automatically. Completion of writing robot can be done by adding the image conversion process from bmp format to svg format so that robot does not read the edges of the input image in order to the resulting writing is not in the form of two lines.
\end{abstract}

Keywords: balinese script, writer robot, transliteration, unicode balinese letter, LBtrans.

\section{Introduction}

The preservation of Balinese script as one of the Balinese culture continues to be enhanced as one of the traditional Indonesian archipelago script developed in Bali Island, Indonesia. This script is commonly used for writing Balinese and Sanskrit languages. The use of Balinese script in writing are in the form of teachings of Religion, geguritan, poetry and other literary works of the Balinese language [1]. In general Balinese script is not used in everyday life and has complex rules. Because of this, the people, especially young children, are less interested and have no motivation to study Balinese script [2]. It certainly will make

ICCSET 2018, October 25-26, Kudus, Indonesia

Copyright (C) 2018 EAI

DOI 10.4108/eai.24-10-2018.2280583 
people increasingly not familiar with the Balinese language which is a Balinese culture. Based on the mentioned above, then various applications are developed to be able to attract and motivate the community in recognizing Balinese script.

One form of preservation is to apply various kinds of Information Technology (IT). There are various applications developed to be able to introduce and also write Balinese script. Some applications that use robots have been developed before. Such as in 2012, it is developed an Application of Balinese script characters Robot Writer based on Nxt-G with Lego Mindstorm Nxt by I. G. N. P. Arimbawa, M. W. A. Kesiman, and I. G. M. Darmawiguna. In this study the implementation environment of robot control software (Bot Removal) is based on Microsoft Visual C \# 2010 and the hardware used is Lego Mindstrom NXT [3]. Whereas the applications are still desktop-based and algorithm in the research has not been able to transliterate Swalalita script. The transliteration result in Balinese script is represented in image format [4].

\section{LBTRANS}

LBtrans is a web-based and mobile transliteration application built using the Correspondent's transliteration engine model. The Balinese script in this algorithm is represented using unicode Noto. This application has covered all scopes of the category of Balinese script writing.

In this algorithm, it uses the corresponding model which is applied through two stages, the first stage is to check the pronunciation of the inserted Latin text. If the speech sound is in the database, then the text based on the speech sound will be transformed into a target grapheme. If it is not in the database, it is modified according to the basic algorithm based on the speech sound into target grapheme [5]. The corresponding model illustration is shown in Figure 1.

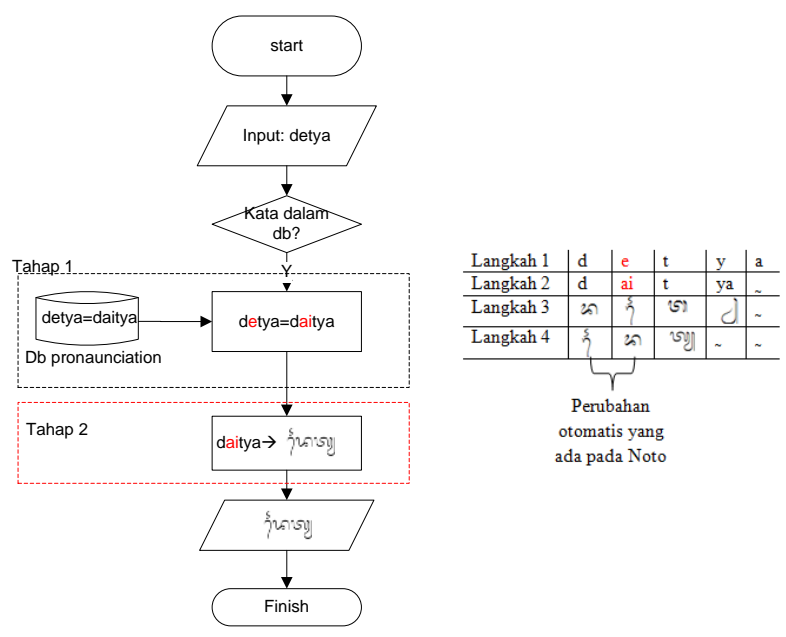

Fig. 1. Corresponding transliteration model in Lbtrans. 


\section{3 mDrawbot}

mDrawbot is a flexible, programmable robot developed by McBlock. mDrawbot can be assembled into four different configurations, ie mScara, mSpider, mEggbot and mCar. Its motherboard is based on Arduino IDE software. mDrawbot is controlled by mDraw software capable of working on different open source platforms. mDraw is a special drawing software designed for mDrawbot.

This study uses mScara as shown in Figure 1, which is connected with Nyuratin application in order to write the resulting image. Scara is short for Selective Compliance Assembly Robot Arm. mScara is an image robot with a type of coordinate of a silendris consisting of two structures.

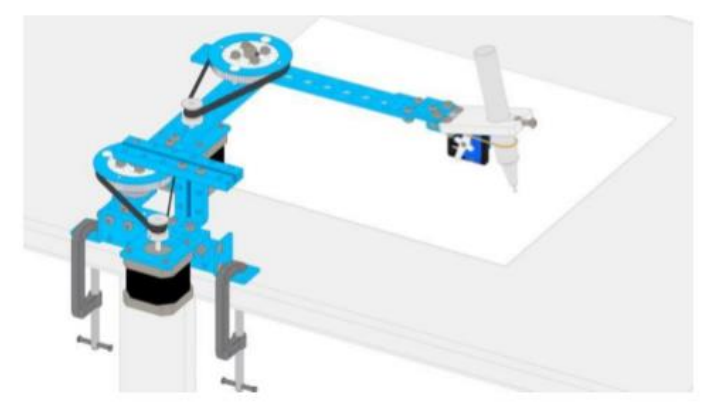

Fig. 2. mScara Robot.

The mDraw software will work after the robot connection process succeeds. Then it is followed by opening the image file. When the bmp image is opened, the image format conversion dialog will appear to convert bmp to svg format. The image will be sent to the robot that will write the image data. After it gives the play command, then the robot will write.

\section{Method}

\subsection{Architectrure}

The user will give input to Lbtrans in the form of Latin text, then the Latin text is transliterated into Balinese script. The transliteration results will be uploaded to the server. The software of the robot will open the transliterated image stored on the server id, then connect with the robot device via usb cable or bluetooth. 


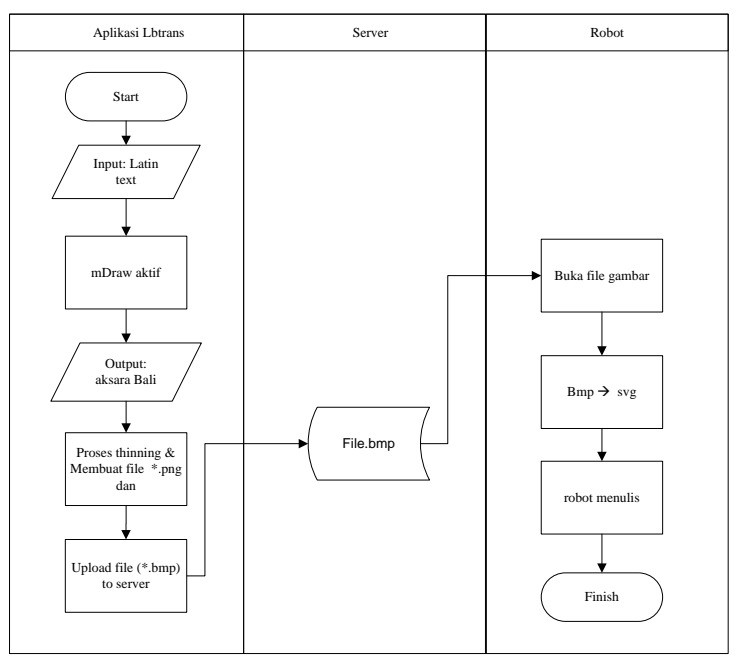

Fig. 3. LBtrans Architecture.

\subsection{Approach}

Automated approach, the result of transliteration is not directly sent into commands to mDrawbot board. The sequence of processes implemented in the robot controller system character writer is as follows:

1. Connecting Bluetooth with robot. Or it can use the data cable instead of the connection tool.

2. LBtrans application will perform transliteration, which produces translation in the form of image element, which in the process is converted into bmp format image.

3. The resulting image is sent to the server through the network. Images will be received on the server side by a web service that instantly parses data and places image files.

4. An agent is placed on the server side, the agent checks for any new images placed on the server. If there is a new image that is stored then the step of a program will be executed to perform sequential commands, they are:

a. The command opens the image file

b. The command converts the selected image format to svg using the potrace application

c. The command plots the svg image into mDraw Gui

d. d. The command runs the drawing operation

Robots accept drawing and running motor on robots to write characters that have been plotted on mDraw Gui.

\subsection{Thinning Process}

The thinning algorithm deliberately removes pixels in binary images, where transitions from 0 to 1 (or from 1 to 0 at other conventions) occur until a situation is met where a set of width per 
unit (one pixel) is connected to a line. The process that occurs in this thining process is, after the glyph Balinese script that is represented by Unicode Noto is converted into image. This image file is converted into greyscale image file, then this image will be converted to binary form. This binary data is processed thinning and converted into PNG and then into BMP format. BMP file ready to convert to SVG to be executed by the robot.

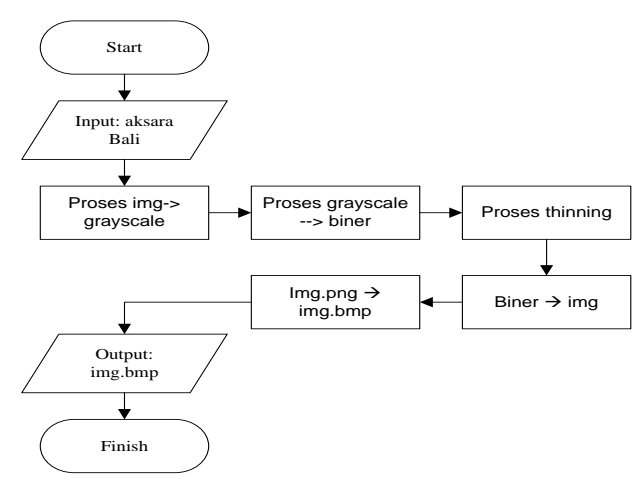

Fig. 4. Image thinning algorithm.

Table 1. Comparison of image results before and after the Thinning process.

\begin{tabular}{|c|c|}
\hline Before thinning & After thinning \\
\hline लभख⿰ & $\begin{array}{c}\text { रาमूण } \\
45\end{array}$ \\
\hline
\end{tabular}

\section{RESULT}

The test of the Balinese script writing process was tested in 152 Sadewa test document cases, with results as in Table 2. The position of the pen on the robot arm is influenced by the configuration of the robotic software. So the image position should be in quadrant II. The size of the writing of a robot depends on the number of Balinese characters in the image that becomes input. The fewer the characters, the larger the font size will be. 


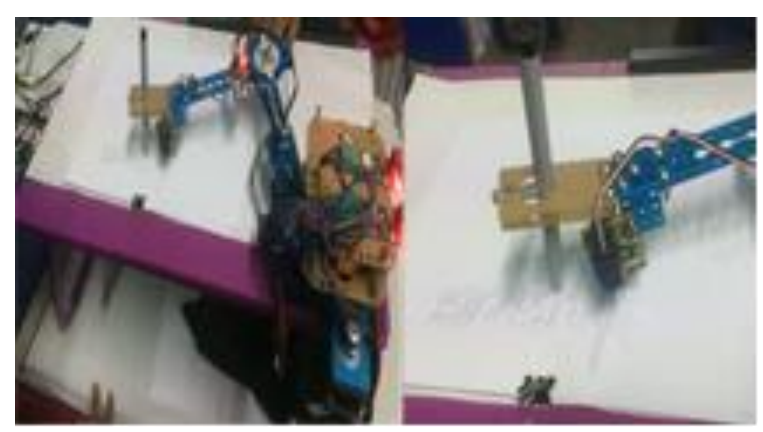

Fig. 5. Writing process.

The process of converting bmp format to svg is done by potrace software which reads the edges of the image, so that the resulting writing is in the form of two lines. To overcome this, the thinning process is done before the image format changes bmp, with the aim of minimizing the distance in the line formed.

The accuracy of the successful test written by the robot is $96.71 \%$. Balinese script form that can not yet be written perfectly is that the ones which have more than 5 characters in a line. This is because the more characters entered, the characters in the image will be smaller thus the image is not clear.

\section{CONCLUSION}

Based on the research that has been done, conclusions can be taken as follows:

1. Web server is required as an intermediary between Nyuratin app and robot to be able to write Balinese script characters and transliterating latin text to Balinese script characters.

2. Images uploaded to web server by LBtrans app are bmp format, so the flow is done by conversing it by potrace program to svg format.

3. The robot can write the transliterated Balinese script on the LBtrans application.

4. The result of written Balinese script produced by Balinese script writer robot with application is averagely correct. The Robot's writing results are influenced by the number of characters transliterated, the fewer the number of characters, the larger and clearer the letters written, and vice versa.

In the next development, it can be that the mechanical design robot character writers can produce Balinese script writing in the form of a line as the original. And the application of Balinese script authors controller without using web service, so it can be directly between robots and the application.

\section{References}

[1] I. D. A. M. Sartini, M. W. A. Kesiman, and I. G. M. Darmawiguna, "Converter, Pengembangan Text to Digital Image Untuk Dokumen Aksara Bali," J. Nas. Pendidik. Tek. Inform., vol. 2, pp. 64-84, 2013. 
[2] I. K. Paramarta and G. Indrawan, Komputerisasi Transliterasi Teks Latin ke Aksara Bali Seri Teknologi Informasi untuk Budaya, 1st ed. Singaraja, 2017.

[3] I. G. N. P. Arimbawa, M. W. A. Kesiman, and I. G. M. Darmawiguna, "Pengembangan Robot Penulis Karakter Aksara Bali Berbasis Nxt-G dengan Lego Mindstorm Nxt," Semin. Nas. Pendidik. Tek. Informartika, vol. 9, no. 5, pp. 160-174, 2012.

[4] I. G. N. P. Arimbawa, M. W. A. Kesiman, and I. G. M. Darmawiguna, "Pengembangan Robot Penulis Karakter Aksara Bali Berbasis NXT-G dengan Lego Mindstorm NXT," in Prosiding Seminar Nasional Pendidikan Teknik Informartika (Senapati), 2012, pp. 160-174.

[5] J. Oh and K. Choi, "An Ensemble of Grapheme and Phoneme for Machine Transliteration," in Second International Joint Conference on Natural Language Processing ( IJCNLP 2005 ), 2005, pp. $450-461$. 